\title{
O "afrocentrismo" e as voltas que o mundo dá: entrevista com Mestre Cobrinha Mansa
}

\author{
Celso de Brito \\ Doutor em Antropologia \\ Professor na Universidade Federal do Piauí \\ celsodebrito@ufpi.edu.br
}

Daniel Granada

Doutor em Antropologia

Professor da Universidade Federal de Santa Catarina

daniel.granada@ufsc.br

Matheus do Monte Marques

Graduando de Ciências Sociais da

Universidade Federal do Piauí

matt_mmq@hotmail.com

Ricardo Nascimento

Doutor em Antropologia

Professor da Universidade da Integração Luso Afro-Brasileira ricardonascimento@unilab.edu.br

Neste quarto número da Revista EntreRios, publicamos a conversa que tivemos com Dr. Cinézio Peçanha, o Mestre Cobrinha Mansa. Exímio capoeirista e um dos grandes responsáveis pela internacionalização da capoeira, Cobra Mansa realizou inúmeras oficinas ao redor do mundo e formou diversos alunos no exterior, que hoje são trenéis, contramestres e mestres da "tradicional" Capoeira Angola. Defensor do discurso da "tradição" das origens africanas da capoeira, Cinézio Peçanha não se limitou a ser mestre de capoeira e buscou validar seu conhecimento na academia, tendo recentemente recebido o título de Doutor.

Dr. Cinézio ou Mestre Cobrinha formou o primeiro grande grupo transnacional de Capoeira Angola, tornando-se responsável por núcleos fixados nos cinco continentes. Nesta entrevista, ele nos conta parte de sua experiência no processo de transnacionalização da capoeira, tanto como capoeirista quanto como pesquisador. Ao entrar em contato com intelectuais africanos e africanistas em meio às suas frequentes viagens pelo mundo, desenvolveu conceitos que se materializaram em produções intelectuais, sobretudo em sua tese de doutorado intitulada Gingando na linha da Kalunga: Capoeira Angola, Engolo e a construção da Ancestralidade, defendida em 2019 no Programa Multi-institucional e Multidisciplinar em Difusão do Conhecimento da Universidade Federal da Bahia.

A entrevista aqui transcrita procurou dar conta do que consideramos como essencial no pensamento do Mestre. Inicialmente, exploramos sua visão sobre a capoeira e a Capoeira Angola, bem como as inúmeras apropriações e significados que ela adquire em seu processo de transnacionalização e os desafios envolvidos neste processo de acordo com a visão de um de seus atores principais. Em seguida, exploramos questões sobre a africanidade da capoeira e os resultados de sua pesquisa de tese. Finalmente, Cobra Mansa deixa um questionamento pertinente aos replicadores de citações de pesquisa- 
-dores europeus, nos instigando a buscar novas ferramentas conceituais oriundas do sul global ou, como defende ele, de autores afrocêntricos para dar conta da explicação das práticas afrodescendentes. Quem sabe este seja um novo desafio a ser enfrentado pelas novas gerações de pesquisadores para a compreensão desta arte em movimento, nas voltas que o mundo dá. Boa leitura e "vâmo s'imbóra" Camarada!

\section{Situando a Capoeira Angola}

\section{EntreRios: O queé Capoeira Angola, mestre?}

Dr. Cinézio Peçanha, Mestre Cobrinha Mansa (M.C.M.): Olha, eu diria hoje que a Capoeira Angola é um complexo de danças, lutas e rituais que vieram principalmente da região bantu da África para o Brasil. Acredito que os povos bantus chegaram ao Brasil e encontraram elementos culturais com os quais se identificaram, uniram tudo e criaram algo que não existia em nenhum outro lugar. Então a capoeira, para mim, tem influência dessa africanidade, mas o local onde isso tudo se juntou foi aqui no Brasil. Ainda acho muito difícil aceitar as teorias sobre a origem indígena da capoeira porque ainda não encontrei elementos que pudessem me dar maiores pistas sobre isso. Mas não é uma coisa a ser descartada totalmente... Agora, é muito importante a gente entender que quando falamos de capoeira estamos falando de uma cultura em constante transição. A capoeira que nós conhecemos hoje, em 2020, não é a mesma capoeira da década de 30 ou de 40. Quando analisamos os filmes e fotos desse período vemos que a movimentação mudou, mas também é importante perceber um fio de fundamento que marca uma continuidade.

Hoje em dia, eu vejo assim: a educação que a gente recebe é muito linear e não dá muita margem para você passear dentro das coisas, é assim "ou" é assim! Mas, quando você amplia um pouco a visão, percebe que pode ser assim, "mas também" pode ser assim, vai depender do momento. As pessoas perguntam: "Ah, mas capoeira é luta ou é dança?", e eu digo: "Pô, não sei, você quer dançar, quer lutar ou quer brincar?" Isso vai depender do momento. Nossa necessidade de categorizar as coisas às vezes acaba prejudicando nosso conhecimento.

\section{EntreRios: Quais os sentidos atrelados à capoeira hoje na opinião do senhor?}

M.C.M.: Para mim, a capoeira isolada não significa nada. Por quê? A capoeira só é feita a partir do momento que nós temos capoeiristas unidos. A capoeira como pensamento isolado se dissolve. As pessoas que estão envolvidas diretamente com a capoeira se transformam e são transformadas através da capoeira. Nessa relação a capoeira ganhou diversos significados. Eu acho que para as pessoas que estão mais envolvidas ela é um movimento social. Essas pessoas atribuem um significado mitológico e ideológico para a capoeira: a capoeira como movimento de libertação.

Nesse sentido, a capoeira é entendida como uma ferramenta que pode ser usada para libertar não simplesmente a pessoa, mas também a sociedade das amarras do sistema em que vivemos. Por outro lado, não dá para definir a capoeira simplesmente dessa forma porque justamente no momento político em que vivemos no Brasil existem capoeiristas de extremadireita! Então, como é que a gente pode lidar com esse dois polos da capoeira? Um polo no qual a pessoa acredita que a capoeira é um elemento de libertação do próprio sistema e do próprio ser humano e o outro que usa a capoeira para oprimir as pessoas?

De minha parte, uso uma pergunta que foi feita pelo Mestre João Pequeno, quando lhe perguntaram sobre o que ele achava da capoeira ficar submetida às normas do Conselho de Educação Física: "Olha, se a Capoeira serve como luta de libertação, como é que agora ela vai nos aprisionar? Acho que é tudo isso. 


\section{Os processos transnacionais e as questões de classe e raça}

\section{EntreRios: Por que o senhor saiu do Brasil?}

M.C.M.: Eu não tinha intenção de sair realmente do Brasil, mas o Mestre Jelon me convidou para ir aos Estados Unidos e fazer uma oficina. Quando cheguei lá, a ideia dele era me levar para o Texas, para dar aula numa universidade onde ele tinha conseguido um contrato. Eu ia dar aula numa universidade, com um salário e carga horária definida e participar do espetáculo de dança dessa universidade.

Mas o Texas era longe de tudo, Mestre João Grande estava em Nova York... Eu pensei um pouco e acabei fazendo uma oficina em Nova York e fui convidado por um professor da Ausar Auset Society (AAS) para trabalhar em Washington D.C. Então fui e vi que todas as atividades da AAS eram afrocentradas. Década de noventa e tal, super empolgado com essa questão toda. "Pô, que legal". Aí o Mestre Rogério, que estava morando na Alemanha, me convidou para dar uma oficina por lá. Eu fui e, quando estava na Alemanha, o professor da AAS me convidou novamente para trabalhar com ele por três meses. Voltei aos Estados Unidos e fiz o trabalho, e esse profesor conseguiu extensão do meu visto e eu fiquei mais três meses. Depois disso, ele me pediu para ficar lá mais tempo, então comecei a estudar numa escola bilíngue, fiz o TOEFL e depois de um ano surgiu uma oportunidade de estudar na Universidade do Distrito da Columbia, na UDC. Eu fiz 2 anos de Antropologia e Sociologia. Comecei a dar aula em várias escolas, foi quando eu tive uns desentendimentos com o GCAP [Grupo de Capoeira Angola Pelourinho] e me desliguei do Grupo Pelourinho. Em 1996, criei a Fundação Internacional de Capoeira Angola (FICA), que inclusive é inspirada no Mestre Jelon, que tinha a International Capoeira Foundation, então eu fiz a International Capoeira Angola Foundation.

\section{EntreRios: E oretorno, mestre? Por queéque o senhorvoltou?}

M.C.M.: O retorno foi um pouco mais complicado, foram muitos motivos. Eu já tinha planos de voltar, mas com o 11/091 eu me decidi. Pensava que tinha coisas importantes para fazer no Brasil e nunca perdi o vínculo com o meu país. Morava nos EUA, mas todo ano eu vinha ao Brasil. No ano em que eu não consegui vir, meus alunos brasileiros fizeram uma vaquinha e compraram uma passagem pra mim. O Mestre Valmir ficava três meses nos EUA e eu ficava três meses no Brasil, em dezembro, janeiro e fevereiro.

EntreRios: Hoje em dia, o senhor acha que tem alguma diferença entre seus alunos brasileiros e seus alunos estrangeiros?

M.C.M.: Eu diria que o capoeirista estrangeiro enfrenta dificuldades para entender e sentir a capoeira. A primeira barreira é a língua, mas a segunda é o ambiente e a lógica da capoeira. O capoeirista que aprende capoeira e só viveu na Europa não tem um ambiente social de confronto e conflito como uma pessoa que vive no Brasil. Mas eu tenho que fazer uma ressalva: as pessoas que têm grandes dificuldades na vida, no seu dia a dia, conseguem entender a capoeira melhor. O menino que foi criado em apartamento tem um pouco mais de dificuldade, porque ele vive num mundo confortável, já o menino que foi criado na rua está acostumado a improvisar rapidamente.

Quando eu comecei a dar aulas nos Estados Unidos, tinha essa concepção de que "Ah, o americano não aprenderá capoeira! Mas quando eu dei aulas para crianças americanas negras ou crianças em situação de rua, percebi que elas aprendem facilmente, do mesmo jeito que as crianças aqui do Projeto Axé da Bahia aprendem. Eles entendem, por exemplo, conceitos básicos da filosofia da capoeira: "entrar saindo, sair entrando", "fingir ir, mas não ir". São situações desenvolvidas no dia a dia de algumas pessoas e não no de outras. A cosmovisão, a visão de mundo dessas pessoas é diferente.

1 Data dos atentados às Torres Gêmeas em 2003.

EntreRios - Revista do PPGANT -UFPI -Teresina • Vol. 2, n. 2 (2019) 
EntreRios: Daria para dizer que essa distinção seria menos cultural ou nacional do que de classe?

M.C.M.: Eu diria que sim, os dois marcadores influenciam no aprendizado e na maioria dos casos correspondem sim, mas também diria que em algumas vezes não há correspondência entre classe social, cultura nacional e experiência de vida. A gente vai pegar um Antônio Carlos Magalhães ${ }^{2}$, né, que era de uma família abastada, mas foi capoeira e vivia a malandragem da rua, pensava como um capoeirista (risos).

EntreRios: Como se dá na prática a relação entre a capoeira e a negritude?

M.C.M.: A gente não pode negar que a origem da capoeira está conectada à África, então para a pessoa negra será muito mais fácil surgir uma identificação e, quando surge a identificação, surge questionamento. Eu conheço várias pessoas que foram se conhecer como pessoas negras depois que começaram a praticar a capoeira.

EntreRios: Sabemos que a capoeira tem capoeiristas de muitas etnias e que não faz questão de atender apenas a negros. No caso americano, em que existe um sistema étnico muito polarizado, isso causa algum conflito?

M.C.M.: Eu tive um grupo de alunos nos EUA que era afrocentrado mesmo, radicais. No entanto, o convívio deles com a capoeira gerou outra coisa, os forçou a conviver com brancos e gerou um entendimento mútuo a partir do conflito. O conflito não foi negativo, ao contrário, foi positivo. Acho que eles se mantiveram afrocentrados, mas agora eles são pessoas que entendem uma parcela do outro lado, porque viveram o outro lado também. Por exemplo, Gegê, Leonel e Jussara, que foram as primeiras pessoas brancas a treinarem capoeira comigo nos EUA, tiveram experiências terríveis dentro de um grupo afrocentrado, mas que, tanto para um lado quanto para o outro, foram muito proveitosas. Hoje em dia, Gegê e Sequé, Gegê e Kamal são amigos. Mas na época não se davam bem, não! Os dois lados não se conheciam e foi a capoeira que os colocou em contato. A gente tinha, uma vez por mês, uma reunião só para discutir questões que julgávamos importantes, e começou com a questão racial/étnica, porque eu tinha alunos japoneses, coreanos, indianos. Uma vez por mês alguém falava sobre sua cultura e depois discutíamos, e alguém trazia comidas típicas. Eu fui aprendendo muito sobre as condições daquelas pessoas, por exemplo: não sabia que os coreanos viviam uma inferioridade com relação aos japoneses que é correspondente à relação entre negros e brancos nas Américas. Hoje todos convivem e conversam... Mas foram anos, não foi um, nem dois anos, mas sim cinco, seis anos de conversas conflituosas todos os meses.

EntreRios: A gente falou de outras modalidades de capoeira que estavam embranquecendo a capoeira e que a Capoeira Angola lutou pela africanidade. O senhor acha que se fosse outra modalidade de capoeira e não a Capoeira Angola que puxasse esse debate nos EUA, esses conflitos teriam gerado essas consequências positivas também? Por exemplo, se fosse o Mestre Jelon ou outras pessoas de outros segmentos da capoeira?

M.C.M.: Sim, mas o Mestre Acordeom também sofreu com isso, o Mestre Jelon também sofreu com essas questões. Aluno de Jelon e do Acordeom, o Timba, depois foi ser aluno do GCAP porque o Acordeom sempre tentou negar esse conflito de uma certa forma. E aí o que é que aconteceu? Quando o aluno dele veio ao Brasil e começou a conhecer a capoeira como um todo, até essa questão de dizer que "capoeira é uma só" ruiu, né? Esse foi o questionamento que existiu nos Estados Unidos durante muitos anos. Os primeiros diziam que "capoeira é uma só, não existe esse negócio de estilo, tudo é capoeira" , mas quando o pessoal vem ao Brasil na década de 80 e percebe que aqui o conflito estava acirrado, o que é que vai acontecer? O pessoal vai ver "Não, tem uma capoeira, e tem outro tipo de capoeira, a Capoeira Angola".

2 Conhecido personagem atuante na política baiana e nacional (1927 - 2007).

EntreRios - Revista do PPGANT -UFPI -Teresina • Vol. 2, n. 2 (2019) 
E tem alguns alunos que ficam decepcionados com isso. Então, o próprio Timba é um deles, que sai da Regional, entra na Capoeira Angola e radicaliza o seu discurso afrocêntrico.

EntreRios: Pensando nesse processo de construção e reconstrução de pertencimento étnico e de revisão das relações entre negros e brancos, entre brasileiros e americanos, sobretudo depois do trabalho com a Ausar Society, o senhor acha que a Capoeira Angola se alterou?

M.C.M.: Olha, ao mesmo tempo em que eu poderia dizer que sim eu diria também que não. A década de 90 é marcada por um afrocentrismo generalizado na Capoeira Angola em resposta à branquidade da capoeira que estava em curso. Na década de 1990, tanto acadêmicos quanto militantes se envolvem diretamente com a Capoeira Angola em oposição àquela capoeira e tal... Quando os intelectuais e militantes afrocentrados e afrocêntricos entram é que ela começa a desviar desse caminho "nacionalista" e se torna afro-brasileira. Então, eu posso dizer que Ken Dossar, Daniel Dawson, Fu'Kiau, a Ausar Auset Society, Timba Mashama, o próprio GCAP, tudo isso surge em um momento, é uma década, e essa década é a década de 1990. O Ed Powe, o T.J. Obi, muita gente começa a se envolver com a Capoeira Angola levando discussões e trazendo o discurso afrocêntrico para dentro da Capoeira. E foi o GCAP em Salvador e o GCAP no Rio de Janeiro, junto com o IPCN (Instituto de Pesquisa Negra), inclusive era o mestre Braga Neto quem dava aulas lá no IPCN, a galera do MNU... Foi uma efervescência de militância. Junte isso à influência do Fu'kiau, Robson Fals Thompson... Aliás, são eles que vão trazer essa discussão de que existem outras lutas similares em outras partes do mundo porque até então a gente tinha a concepção de que a capoeira era a única. Até a década de 80, isso era muito aceito. Ou seja, houve uma aglutinada de culturas negras das Américas. Tudo isso influenciou o que a Capoeira Angola é hoje no mundo.

Por isso, a gente tem de admitir que houve uma reafricanização da capoeira depois da década de 1980, principalmente da Capoeira Angola. Além do que foi dito acima, a gente percebe que o GCAP e o Mestre Moraes, por exemplo, começou a fazer músicas que usavam mais palavras em yorubá. O Nzinga trouxe vários elementos da religião Bantuboto pra dentro da capoeira e a própria FICA,trazendo o cosmograma bakongo com o Dr. Fu'kiau... Inclusive uma das camisas que a gente usava na década de 1990 era com o símbolo do cosmograma bakongo de Fu'kiau...

Outra coisa que surge na capoeira e que é característico desse processo todo de circulação pela mundo foi a Bolsinha de carregar berimbau, que hoje em dia é super usada por quase todos os capoeiristas do mundo, inclusive no Brasil, e aquilo veio das bolsas de carregar esqui de neve! Na Europa ou nos EUA um berimbau era um instrumento muito valioso e tinha que ser guardado muito bem, ele valia 100 euros ou 80 dólares! Além disso, são os livros de músicas e as técnicas de aprendizado por anotação em caderno. Hoje as escolas brasileiras têm isso, mas na década de 1980, 1990, era só fora do Brasil... No Brasil, era apenas pesquisador que fazia isso com a relação de música de capoeira que tem no livro de Waldeloir Rêgo, de 1968.

\section{EntreRios: O mestre que ensina fora do Brasil volta ao Brasil diferente?}

M.C.C.: Sim, ele se adapta e traz pra cá o que aprendeu. A própria didática, a forma de se comportar do capoeirista... O capoeirista que vai pra fora do Brasil se adapta à nova realidade, ele aprende a lidar com outras situações, com outras instituições. Para dar um exemplo bem prático, o capoeirista sai do Brasil batendo em todo mundo, mas quando ele chega em outros países menos tolerantes com a violência, ele tem que mudar, de um jeito ou de outro. Teve capoeirista que foi processado na Inglaterra porque deu uma porrada num cara numa roda de capoeira. Esse cara quando volta, volta considerando outras experiências sobre a violência, inclusive. 


\section{Afrocentrismo na Capoeira Angola transnacional}

EntreRios: Parte da posição que o senhor tem sobre capoeira e africanidade vem da relações que manteve com Dr. Fu'kiau. Como isso começou?

M.C.M.: Eu fui para o EUA em 1994. Em 1996, eu o trouxe para Salvador... Creio que o conheci em 1992 ou 1993, no Schomburg Center for Research in Black Culture, quando Robert Farris Thompson fez uma exposição chamada "Dancing Between Two Worlds", Dançando Entre os Dois Mundos. Ele levou um pessoal da Ladja, nós da capoeira e Dr. Fu'kiau para fazeres palestras. Estávamos eu e Mestre Moraes ainda no Grupo Pelourinho.

Na palestra, Dr. Fu'Kiau falava do cosmograma bantu, da espiritualidade bantu e que a capoeira fazia parte dessa filosofia. O Ken Dossar e o Daniel Dawson já diziam que a capoeiratinha todos os elementos da cultura africana, inclusive a tese do Ken Dossar era baseada nas perguntas sobre os elementos da Capoeira Angola que caracterizam a influência da cultura africana. E ele conclui: "a capoeira se encaixa nesse, nesse, nesse, nesse e nesse".

Nesse mesmo período, eu encontrei a Makota Valdina aqui no Brasil e ela falava que a Capoeira Angola não poderia estar dissociada do candomblé de Angola, é tudo uma coisa só... Mas depois que eu conheci Dr. Fu'kiau, eu passei a convidá-lo para todos os eventos de Capoeira que nós tínhamos lá nos EUA, para ele palestrar.

EntreRios: E o senhor trazia ele para todos eventos do seu Grupo no Brasil também?

M.C.M.: Não, ele só veio ao Brasil duas vezes. Ele veio uma vez trazido por mim e outra vez trazido pela Makota Valdina.

EntreRios: A vinda dele teve um caráter formativo dentro do seu trabalho e da Capoeira Angola?

M.C.M.: Eu acabei ficando fascinado com o pensamento dele. Então eu comecei a trazê-lo para perto de mim, para entender mais sobre essa questão da cultura bantu. Eu percebi que havia uma ligação muito grande entre as coisas que a gente aprendia na capoeira, sobre capoeira, e as coisas que ele falava sobre a cultura bantu: ancestralidade, senilidade...

EntreRios: Mas olhando particularmente para a capoeira, ele via isso?

M.C.M.: Ele via isso. Para ele, a capoeira era uma manifestação das lutas que já tinham lá no Congo e que vieram para o Brasil, ela só mudou de nome aqui. Ele chamava de "Kipura", K-IP-U-R-A, que quer dizer "lutar como ave", "lutar como galo", pulando. Dizia que era próxima de uma luta que se praticava pulando. Mas quando eu fui conhecer as lutas africanas percebi que essa luta da qual ele falava tinha mais a ver com a Kabangula.

\section{EntreRios: Dr. Fu'kiau não falava sobre a relação entre N'golo e Capoeira?}

M.C.M.: Não, não. Para ele o N'golo era só mais uma manifestação. Hoje em dia eu entendo, porque tem a Kabangula, tem o Djambo e tem o N'golo. Quando você olha as três sem uma lente eurocêntrica que tende a colocar tudo dentro de uma mesma caixinha, você percebe que são parecidas , mas uma usa mais o pé, a outra usa mais a mão, a outra pode jogar no chão, a outra não pode jogar... Todas são brincadeira, mas cada uma com suas especificidades que no Brasil podem ter se juntado. 
EntreRios: Mestre, o que, na sua opinião, significou a ideia que o senhor ajudou a legitimar sobre o N'golo ser a raiz da Capoeira Angola?

M.C.M.: Eu acho que era uma forma de religação necessária com a África.

Quando o Neves de Souza encontra com Câmara Cascudo na década de 1960 e eles disseminam essa ideia no Brasil, ela não teve um impacto muito grande, inclusive foi contestada pelo Waldeloir Rego em 1968. Essa teoria hoje também é facilmente negada pelos estudos. Mas, na década de oitenta, existiu essa necessidade política, a necessidade de se combater a "brasilidade" ou "branquitude" que existia dentro da capoeira. A capoeira estava se tornando o "esporte nacional", a luta "genuinamente brasileira". Mas, quando o GCAP e outros angoleiros adotaram o N'golo, que quer dizer a "Dança da Zebra", como a origem da capoeira, retomando a ideia de Neves e Souza e Câmara Cascudo e levando para a década de 1980, ficou uma coisa quase incontestável, não tinha como as pessoas dizerem que não era real. Essa retomada pegou muitas pessoas da capoeira de surpresa e depois os próprios estudiosos, porque era uma coisa que estava meio esquecida no tempo e na década de oitenta explode, “boom!”.

Dá uma "materialidade" à ligação política entre Brasil e África que a gente procurava e, apesar dessa "materialidade", a gente nem acreditava que o N'golo ainda existisse, a gente achava que era uma dança que veio e que já tinha se acabado.

Então, teve um efeito muito forte porque a partir daí a capoeira, que era brasileira, que era o "esporte brasileiro" começou a se tornar afro-brasileira e eu acho que a grande sacada do N'golo foi exatamente esta: fazer com que as pessoas apoiassem o olhar, deslocassem do Brasil e dessem uma olhadinha mais para longe, para as raízes africanas.

EntreRios: Como foi para o senhor, um dos militantes legitimadores da ideia do N'golo, tornar-se um de seus maiores críticos?

M.C.M.: A minha pesquisa me mostrou que é pouco provável que a capoeira tenha surgido exclusivamente do N'golo. A desconstrução é um momento muito difícil pra todos, né?! Por isso, eu acho que a minha pesquisa vai levar um tempo sendo criticada, exatamente porque ela mexe com uma crença que fez sentido durante muitos anos e que deu significado para o que nós estamos fazendo hoje. Mas, para mim, aquilo fez sentido naquele momento, já não precisamos de um argumento que pode ser facilmente deslegitimado, agora a gente pode construir outras ferramentas mais sólidas com o mesmo significado político.

\section{Finalizando a conversa}

EntreRios: Prafinalizar, o que o senhor acha importante de dizer e que faltou nesta conversa?

M.C.M.: Já que a gente está dentro da academia, acho importante lembrar que devemos considerar e respeitar outras formas de conhecimento, assim como lembrar da dificuldade prática de fazer isso.

Ainda é muito difícil construir um discurso considerando outras referências, referências não eurocêntricas. O processo de legitimação do conhecimento produzido assim é muito complicado e desanimador, inclusive o reconhecimento de pensadores não eurocentrados é difícil entre os supostamente "parceiros", entre muitos dos intelectuais afrocentrados.

Um dia eu fiz uma camiseta que causou uma polêmica muito grande: era o cosmograma bakongo escrito assim: "Menos Foucault e mais Fu'kiau”. Caramba, a galera caiu matando. "Mas por que Foucault? Foucault é tão legal, e não sei o quê... e pa, pa, pa...". Aí eu pensei comigo assim, "eu gostaria que vocês defendessem os pensadores africanos com a mesma garra e fervor com que vocês defendem Foucault". Eu gostaria de ver isso. E os nossos? "Será que vocês seriam capazes de defender com unhas e dentes as nossas teorias?" 